\title{
ChemComm
}

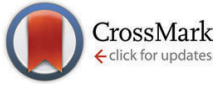

Cite this: Chem. Commun., 2016, 52,1673

Received 2nd November 2015, Accepted 4th December 2015

DOI: $10.1039 / \mathrm{c5cc09075}$

www.rsc.org/chemcomm

\section{Simultaneous cellulose conversion and hydrogen production assisted by cellulose decomposition under UV-light photocatalysis $\dagger$}

\author{
Guan Zhang, ${ }^{{ }^{a}}$ Chengsheng $\mathrm{Ni}^{,}{ }^{a}$ Xiubing Huang, ${ }^{a}$ Aakash Welgamage, ${ }^{b}$ \\ Linda A. Lawton, ${ }^{b}$ Peter K. J. Robertson ${ }^{c}$ and John T. S. Irvine*a
}

\begin{abstract}
Photocatalytic conversion of cellulose to sugars and carbon dioxide with simultaneous production of hydrogen assisted by cellulose decomposition under UV or solar light irradiation was achieved upon immobilization of cellulose onto $\mathrm{a} \mathrm{TiO}_{2}$ photocatalyst. This approach enables production of hydrogen from water without using valuable sacrificial agents, and provides the possibility for recovering sugars as liquid fuels.
\end{abstract}

Economic and efficient methods for production of hydrogen, especially those that can generate hydrogen utilizing renewable energy resources (e.g., water, solar and biomass), are currently the subject of extensive research. Solar hydrogen production from water splitting via a photocatalytic or photoelectrochemical process is considered as one of the potentially promising methods. ${ }^{1}$ Although photocatalytic hydrogen production from water splitting has been demonstrated a few decades ago, ${ }^{2}$ photocatalysts that efficiently generate hydrogen from pure water (without sacrificial agents) have not been extensively reported..$^{3-5}$ In most cases, the photocatalytic hydrogen production from water is performed with an excess of electron donors such as alcohols, sugars and organic acids/amines. ${ }^{6-10}$ A more practical and economical case for hydrogen production, however, would not involve the use of such valuable chemicals as the electron donors. ${ }^{11}$

Lignocellulosic material as the most abundant component of biomass is being considered as a promising renewable resource for sustainable hydrogen production. Cellulosic biomass can be converted into hydrogen and other valuable products through several thermochemical processes such as steam gasification, fast pyrolysis and hydrolysis by acids or enzymes. ${ }^{12}$ Because of the rigid intra- and inter-molecular hydrogen bonds in cellulose, the conversion of cellulose to platform molecules (e.g. sugars) for preparation of liquid

\footnotetext{
${ }^{a}$ School of Chemistry, University of St Andrews, St Andrews KY16 9ST, UK. E-mail: gz23@st-andrews.ac.uk, jtsi@st-andrews.ac.uk

${ }^{b}$ Innovation, Design \& Sustainability Research Institute, Robert Golden University, Aberdeen AB10 1FR, UK

${ }^{C}$ Centre for the Theory and Application of Catalysis (CenTACat), School of Chemistry and Chemical Engineering, Queen's University Belfast, David Keir Building, Belfast BT9 5AG, UK

$\dagger$ Electronic supplementary information (ESI) available. See DOI: 10.1039/c5cc09075j
}

fuels and high-value chemicals normally requires extremely harsh reaction conditions (e.g. high temperature and/or high pressure). ${ }^{13,14}$ On the other hand, the separation and purification of the valuable bio-products from the reaction medium is rather difficult, which is still an issue to be resolved for the practical application.

If cellulose could be photocatalytically decomposed into the platform molecules, the valuable bio-products for liquid fuels production can be in situ harvested with the application of appropriate reactor engineering. In the meantime, it is possible to obtain hydrogen during the cellulose decomposition process, by utilizing the cellulose and the as-generated intermediates as the sacrificial electron donors. The hydrogen production assisted by the cellulose decomposition may also be more practical and feasible compared to the photocatalytic water splitting. ${ }^{15}$ Only a few examples of the photocatalytic cellulose degradation have been reported, ${ }^{16-18}$ but the degradation of cellulose with the simultaneous generation of hydrogen is limited. In this work, we report the development of a relatively simple process for immobilizing cellulose onto a solid photocatalyst (e.g. $\mathrm{TiO}_{2}$ ). Upon UV light irradiation, the simultaneous hydrogen production from pure water and efficient cellulose conversion to carbon dioxide via the formation of sugar intermediates was achieved as shown in Scheme S1 (ESI $\dagger$ ). This approach has, hence, opened a new way of solar driven hydrogen production from water accompanied with the conversion of cellulose to valuable platform molecules.

Firstly, a cellulose colloidal aqueous suspension was prepared by two-step ball-milling (details see ESI $\dagger$ ) of crystalline $\alpha$-cellulose powder (Sigma-Aldrich, size ca. 10-1000 $\mu \mathrm{m}$ estimated from SEM image and particle size analysis (Fig. S1 and S2, ESI $\dagger$ )). The mechanochemical pre-treatment significantly cuts down the microcrystalline cellulose into sub-micron sized (ca. $0.1-3 \mu \mathrm{m})$ cellulose particles (Fig. S3, ESI $\dagger$ ), which could be easily suspended in water (Fig. S4, ESI $\dagger$ ). Upon the dispersion of platinized $\mathrm{TiO}_{2}$ (P25, BET surface area $\sim 50 \mathrm{~m}^{2} \mathrm{~g}^{-1}$, particle size $\sim 20-30 \mathrm{~nm}$, loading of $0.5 \mathrm{wt} \%$ platinum for $\mathrm{H}_{2}$ production, hereafter denoted as $\mathrm{TiO}_{2}(\mathrm{Pt})$ ) photocatalyst nanoparticles $(0.1 \mathrm{~g})$ into a $250 \mathrm{ml}$ aqueous solution filled with certain amount of the cellulose suspension stock $(8 \mathrm{ml}, 20 \mathrm{ml}, 40 \mathrm{ml}$ and $80 \mathrm{ml})$ by sonication 
and stirring, the cellulose@ $\mathrm{TiO}_{2}(\mathrm{Pt})$ composite powder was obtained by filtering the mixed colloidal suspension. An excess of water was used to wash out the trace amounts of soluble sugars (glucose oligomers produced from ball-milling) that possibly remained on the mixed composite powder. Finally, the cellulose immobilized $\mathrm{TiO}_{2}(\mathrm{Pt})$ powder was obtained after drying the powder in air under room temperature, and denoted as TC1, TC2, TC3, and TC4 for the samples prepared from $8 \mathrm{ml}$, $20 \mathrm{ml}, 40 \mathrm{ml}$ and $80 \mathrm{ml}$ cellulose suspension, respectively.

The facile "mixing and drying" based immobilization procedure and the possible reactions taking place between the cellulose and $\mathrm{TiO}_{2}$ nanoparticles are illustrated in Scheme S2 (ESI $\dagger$ ). It has been well documented that organic compounds with multiple hydroxyl groups (e.g. catechol, phenolic resins) can easily bind with $\mathrm{TiO}_{2}$ nanoparticles via their hydroxyl groups and form surface "Ti-ligand" complexes. ${ }^{19}$ The cellulose nanoparticles, consisting of poly-hydroxyl groups on linked glucose units, are thus expected to be able to anchor with $\mathrm{TiO}_{2}$ nanoparticles via the surface complexation. The ball-milled cellulose particles have very strong "self-polymerization" ability, which can be evidenced by the fact that the "selfpolymerization" induced particle size growth of cellulose particles takes place in aqueous solution. Without mixing with $\mathrm{TiO}_{2}$ nanoparticles, a white cellulose polymer flake as shown in Fig. S5 (ESI $\dagger$ ) was obtained after drying the cellulose particles at room temperature. Therefore, the grafting of sub-micron sized cellulose particles onto $\mathrm{TiO}_{2}$ nanoparticles can be reasonably ascribed to two pathways: condensation of surface hydroxyl groups and formation of intra-molecular $\mathrm{H}$-bonds between the cellulose strands and $\mathrm{TiO}_{2}$ as shown in Scheme S2 (ESI $\dagger$ ).

The cellulose coating on the $\mathrm{TiO}_{2}(\mathrm{Pt})$ nanoparticles was initially confirmed by SEM and high resolution TEM (HRTEM) images. Cellulose coating can be clearly distinguished from the cellulose coated samples. A gradually increasing thickness of the cellulose layer on $\mathrm{TiO}_{2}(\mathrm{Pt})$ was observed on increasing the cellulose ratio from TC1 to TC4 (Fig. S6, ESI $\dagger$ ). The representative TEM image of the TC4 sample (Fig. 1a) shows an amorphous carbon overlayer along the $\mathrm{TiO}_{2}(\mathrm{Pt})$ particles boundary, which is assigned to the cellulose loaded on the $\mathrm{TiO}_{2}(\mathrm{Pt})$ surface. The HRTEM images focusing on a single cellulose coated $\mathrm{TiO}_{2}$ particles in the Fig. 1a panel clearly show a thin amorphous overlayer (ca. 3-7 nm)

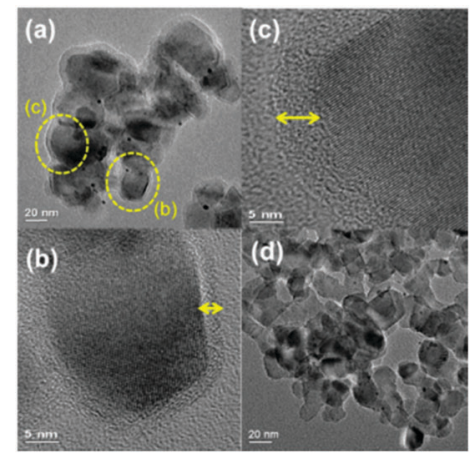

Fig. 1 TEM and HRTEM images of cellulose coated $\mathrm{TiO}_{2}$ nanoparticles $(\mathrm{a}-\mathrm{c})$ and bare $\mathrm{TiO}_{2}(\mathrm{Pt})(\mathrm{d})$. The panel (b and c) are corresponding to selected areas in panel (a). corresponding to a few layers of cellulose strands coating on crystallized $\mathrm{TiO}_{2}(\mathrm{Pt})$ (Fig. 1b and c). No such amorphous layer, however, could be found on the bare $\mathrm{TiO}_{2}(\mathrm{Pt})$ particles (Fig. 1d).

The cellulose content on each immobilized sample (TC1 to TC4) was quantified by thermo-gravimetric differential thermal analysis (TG-DTA) and elemental analysis (CHN). Significant weight loss between $200-300{ }^{\circ} \mathrm{C}$ was observed due to the oxidation of cellulose in air from the TG-DTA analysis (Fig. S7 and S8, ESI $\dagger$ ). A gradual increase in weight loss was observed for the samples along with the increased cellulose loading from TC1 to TC4. Trace amounts $(<0.5 \%)$ of organic impurities on bare $\mathrm{TiO}_{2}(\mathrm{Pt})$ may result from the adsorption of organics during the photodeposition of platinum. The immobilized cellulose contents were determined ca. 3.0\%, 6.5\%, $13.0 \%$ and $20.5 \%$ according to the weight loss for sample TC1, TC2, TC3 and TC4, respectively. In addition, the cellulose contents of different samples from the CHN analysis were summarized in Table S1 (ESI $\dagger)$. Eventhough there are slight derivations of the CHN values and TGA values, the results are generally consistent, indicating the validity of our analysis on the cellulose contents.

The photocatalytic conversion of cellulose was carried out in a de-aerated aqueous suspension of cellulose immobilized $\mathrm{TiO}_{2}(\mathrm{Pt})$ samples (TC1-TC4) by suspending the powder samples in pure water under UV-light irradiation. The concurrent production of $\mathrm{H}_{2}$ and $\mathrm{CO}_{2}$ in gas phase and the soluble cellulose degradation products in aqueous phase were subsequently monitored. Cellulose immobilized bare $\mathrm{TiO}_{2}$ (without Pt, denoted as cellulose@TiO 2 ), mixed cellulose and bare $\mathrm{TiO}_{2}$ (cellulose $+\mathrm{TiO}_{2}$ ), mixed cellulose and $\mathrm{TiO}_{2}(\mathrm{Pt})$ (cellulose $+\mathrm{TiO}_{2}(\mathrm{Pt})$ ) and cellulose immobilized $\mathrm{TiO}_{2}(\mathrm{Pt}$ ) (cellulose@TiO $2(\mathrm{Pt})$ ) samples with the same amounts of cellulose contents were compared for the photocatalytic $\mathrm{H}_{2}$ and $\mathrm{CO}_{2}$ production (Fig. 2). The evolved $\mathrm{H}_{2}$ and $\mathrm{CO}_{2}$ with the $\mathrm{TiO}_{2}(\mathrm{Pt})$ sample during the UV-Visible light irradiation was employed as control. The measured $\mathrm{CO}_{2}$ content in the headspace of reactor was mainly due to the reduced solubility of $\mathrm{CO}_{2}$ in water at elevated temperature ( $293 \mathrm{~K}$ to $313 \mathrm{~K}$ ) during photoirradiation. This can be evidenced by the fact that a similar $\mathrm{CO}_{2}$ production profile was observed during the repeated photoirradiation cycles (as shown in the following part). The $\mathrm{CO}_{2}$ production from the photocatalytic mineralization of trace amount of organic impurities on $\mathrm{TiO}_{2}$ should be negligible. In the presence of TC1 sample, the conversion of cellulose to $\mathrm{CO}_{2}$ was accompanied by the notable production of $\mathrm{H}_{2}$ compared to the control case, whereas the simultaneous production of $\mathrm{H}_{2}$ and $\mathrm{CO}_{2}$ was negligible for the other samples compared with the control. In the case of cellulose@ $\mathrm{TiO}_{2}$ sample, the $\mathrm{CO}_{2}$ production from the cellulose degradation was also found, whereas the cellulose conversion efficiency was much lower than the TC1 sample. The negligible $\mathrm{H}_{2}$ production, along with the lower $\mathrm{CO}_{2}$ production efficiency, suggests the platinum co-catalyst is quite important for the simultaneous cellulose oxidation (enhanced $\mathrm{e}^{-} / \mathrm{h}^{+}$pair separation) and the water reduction (as proton reduction sites). For the physically mixed cellulose and bare $\mathrm{TiO}_{2}$ sample, there was no $\mathrm{H}_{2}$ evolution nor $\mathrm{CO}_{2}$ production from the cellulose conversion, indicating the direct photocatalysis between the cellulose and the $\mathrm{TiO}_{2}$ was negligible. The activities of mixed cellulose and $\mathrm{TiO}_{2}(\mathrm{Pt})$ sample for $\mathrm{H}_{2}$ and $\mathrm{CO}_{2}$ production were similar with the control sample, implying that the cellulose 

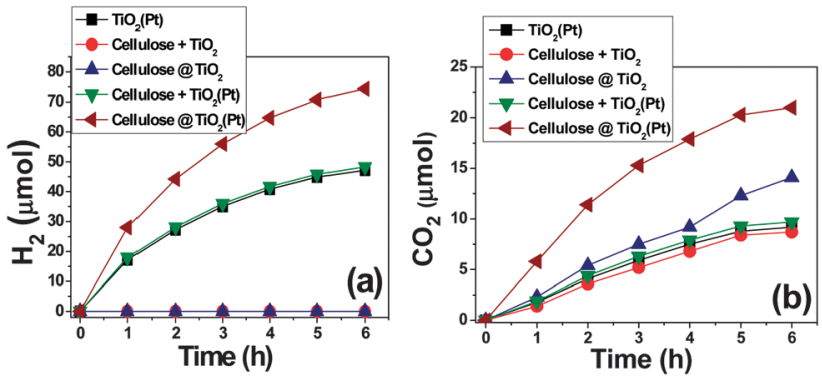

Fig. 2 Time profiles of (a) $\mathrm{H}_{2}$ production and (b) $\mathrm{CO}_{2}$ production from the suspension of $\mathrm{TiO}_{2}(\mathrm{Pt})$, mixed cellulose with $\mathrm{TiO}_{2}$ and $\mathrm{TiO}_{2}(\mathrm{Pt})$, and cellulose immobilized $\mathrm{TiO}_{2}$ and $\mathrm{TiO}_{2}(\mathrm{Pt})$ samples. Reaction conditions: $15 \mathrm{mg}$ samples suspended in $50 \mathrm{ml}$ de-aerated aqueous solution, UV-Visible light irradiation (iron-halide lamp), reaction temperature (293-313 K).

was not evolved in the photoreactions. All of these results demonstrate that the immobilization of cellulose onto $\mathrm{TiO}_{2}(\mathrm{Pt})$ is crucial for the efficient conversion of cellulose.

The photocatalytic production of $\mathrm{H}_{2}$ and $\mathrm{CO}_{2}$ is expected to gradually reduce as the immobilized cellulose is consumed. The time profiles of $\mathrm{H}_{2}$ and $\mathrm{CO}_{2}$ production were measured via the repeated cycles of photocatalysis with the cellulose immobilized $\mathrm{TiO}_{2}$ samples and $\mathrm{TiO}_{2}(\mathrm{Pt})$ as a control. Each photocatalysis run was performed for $6 \mathrm{~h}$ in one day and then the suspension was purged with argon to remove accumulated $\mathrm{H}_{2}$ and $\mathrm{CO}_{2}$ before starting the second cycle. The photocatalysis experiment was repeated up to seven cycles until no significant $\mathrm{H}_{2}$ and $\mathrm{CO}_{2}$ were produced compared to the control. As shown in Fig. 3a and b, the production of $\mathrm{H}_{2}$ and $\mathrm{CO}_{2}$ from the cellulose immobilized $\mathrm{TiO}_{2}$ samples in the first cycle was significantly higher than that from the control $\left(\mathrm{TiO}_{2}(\mathrm{Pt})\right)$. However, the differences for the following cycles gradually decreased because of the depletion of cellulose. In the meantime, the post-tested aqueous solution was analyzed by HPLC after each cycle test. The main soluble
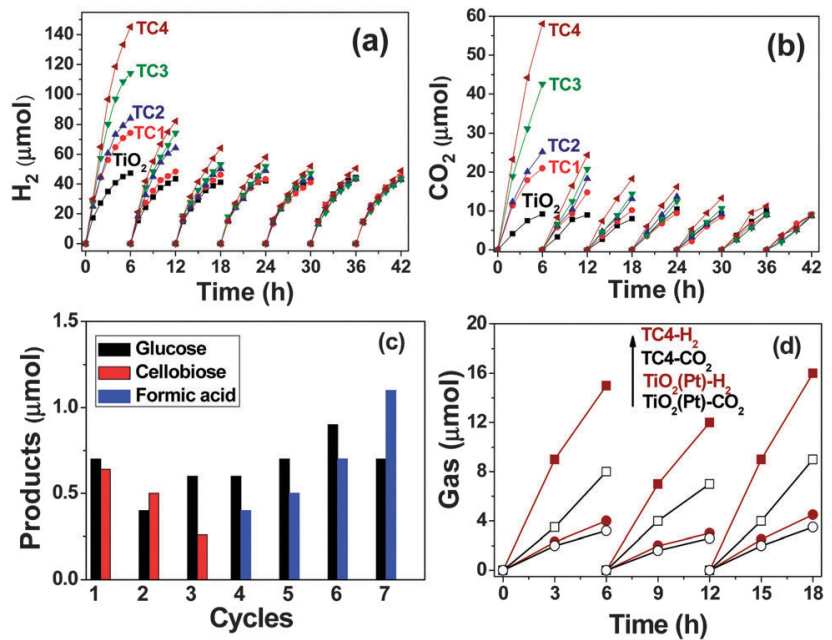

Fig. 3 Time profiles of (a) $\mathrm{H}_{2}$ production and (b) $\mathrm{CO}_{2}$ production from the suspension of $\mathrm{TiO}_{2}(\mathrm{Pt})$ and cellulose immobilized $\mathrm{TiO}_{2}(\mathrm{Pt})$ samples on repeated cycling. (c) HPLC analysis results on the production of cellobiose, glucose and formic acid from the TC4 sample during repeated cycles. (d) $\mathrm{H}_{2}$ and $\mathrm{CO}_{2}$ production from natural sunlight irradiation. products were determined as cellobiose, glucose and formic acid according to the HPLC analysis of standard sugars and acids, while the other products such as cellodextrins, arabinose, erythrose and gluconic acid were negligible (Fig. S9 and S10, ESI $\dagger$ ). Fig. $3 \mathrm{c}$ briefly summarizes the main soluble products that remaining in the reactor from the TC4 sample (as a representative) after each cycle test. The accumulated amount of glucose in each cycle was almost constant, whereas the cellobiose was gradually reduced in the first three cycles and disappeared from the fourth cycle. Only trace amounts of formic acid were detected in the first three cycles (Fig. S10, ESI $\dagger$ ), while the concentration of formic acid gradually increased during the following cycles. Without the light irradiation, the production of gaseous products and organic intermediates were negligible, implying that the total products were generated due to the photocatalytic decomposition of cellulose and its degradation intermediates. Natural sunlight as light source for simultaneous $\mathrm{H}_{2}$ production and cellulose conversion was also tested outdoors. As shown in Fig. 3d, the production rates of $\mathrm{H}_{2}$ and $\mathrm{CO}_{2}$ for TC4 were much higher than those of pure $\mathrm{TiO}_{2}(\mathrm{Pt})$, and they relatively remained constant during the three cycle tests. However, due to the weak solar irradiation intensity, the efficiencies of $\mathrm{H}_{2}$ and $\mathrm{CO}_{2}$ production for TC4 at outdoors were much lower than those obtained with iron-halide lamp source indoors. Without UV-light irradiation, no $\mathrm{H}_{2}$ was evolved for the TC4 sample. (Fig. S11, ESI $\dagger$ ) The solid samples after the repeated photocatalysis tests were further analyzed by SEM and TG-DTA. All the cellulose loaded $\mathrm{TiO}_{2}$ samples expose a smooth and clear surface from the SEM images (Fig. S12, ESI $\dagger$ ), and no significant amounts of cellulose were found by TG-DTA analysis (Fig. S13, ESI $\dagger$ ), which demonstrated that all the cellulose loaded onto $\mathrm{TiO}_{2}(\mathrm{Pt})$ samples was nearly completely decomposed.

Table 1 summarizes the results of the photocatalytic generation of gaseous products $\left(\mathrm{H}_{2}\right.$ and $\left.\mathrm{CO}_{2}\right)$ and liquid products (glucose and formic acid) after seven repeated cycles. The total accumulated $\mathrm{H}_{2}$ and $\mathrm{CO}_{2}$ produced in seven cycles after subtracting those produced from pure $\mathrm{TiO}_{2}(\mathrm{Pt})$ were 35.8, 72.5, 122.5, $195.2 \mu \mathrm{mol}$ $\left(\mathrm{H}_{2}\right)$ and 16.7, 32.0, 53.8, 85.3 $\mu \mathrm{mol}\left(\mathrm{CO}_{2}\right)$ for TC1, TC2, TC3 and TC4, respectively. In addition, the accumulated amounts of glucose $(0.3-0.7 \mu \mathrm{mol})$ and formic acid $(0.5-1.1 \mu \mathrm{mol})$ in aqueous phase were observed for all the cellulose immobilized samples. The total amounts of gaseous and liquid products were increased with more cellulose loading. The $\mathrm{H}_{2}$ and $\mathrm{CO}_{2}$ yields after seven cycles were ca. $80-90 \%$ and $c a .70-80 \%$ respectively, based on the assumption that complete conversion of glucose unit $\left(\mathrm{C}_{6} \mathrm{H}_{10} \mathrm{O}_{5}\right)$ on cellulose to $\mathrm{H}_{2}$ and $\mathrm{CO}_{2}{ }^{20}$ The efficiencies of $\mathrm{H}_{2}$ generation were slightly higher than those of $\mathrm{CO}_{2}$ evolution, because the in situ generated intermediates might not be fully mineralized into $\mathrm{CO}_{2}$. This is also consistent with the results that the observed $\mathrm{CO}_{2} / \mathrm{H}_{2}$ ratios were ca. 0.45 for all the samples, which were slightly smaller than the theoretical value of $0.5 .^{20}$ Furthermore, increasing the immobilized cellulose ratio reduced the cellulose conversion efficiency, as the TC4 sample showed the lowest $\mathrm{H}_{2}$ and $\mathrm{CO}_{2}$ yields. This was also demonstrated by the comparison of total C-balance, which takes account of all generated C-containing products against the initial cellulose content. The TC1 sample exhibited the highest C-balance (93.4\%), whereas the TC4 sample had the lowest one $(75.1 \%)$. 
Table 1 Summarized results on the photocatalytic conversion of cellulose immobilized onto $\mathrm{TiO}_{2}$ after seven photocatalytic cycles

\begin{tabular}{|c|c|c|c|c|c|c|c|c|c|c|}
\hline \multirow[b]{2}{*}{ Sample } & \multirow[b]{2}{*}{$\begin{array}{l}\text { Cellulose } \\
\text { fraction (wt\%) }\end{array}$} & \multirow[b]{2}{*}{$\begin{array}{l}\left(\mathrm{C}_{6} \mathrm{O}_{5} \mathrm{H}_{10}\right) \text { unit } \\
\text { content }(\mu \mathrm{mol})\end{array}$} & \multicolumn{2}{|c|}{$\begin{array}{l}\text { Products } \\
\text { (gas phase) }^{a}\end{array}$} & \multicolumn{2}{|c|}{ Products (aqueous phase) $^{b}$} & \multirow[b]{2}{*}{$\begin{array}{l}\mathrm{H}_{2} \text { yield }^{c} \\
(\%)\end{array}$} & \multirow[b]{2}{*}{$\begin{array}{l}\mathrm{CO}_{2} \text { yield }^{c} \\
(\%)\end{array}$} & \multirow[b]{2}{*}{$\mathrm{CO}_{2} / \mathrm{H}_{2}{ }^{d}$} & \multirow[b]{2}{*}{$\begin{array}{l}\text { C-balance } \\
(\%)\end{array}$} \\
\hline & & & $\begin{array}{l}\mathrm{H}_{2} \\
(\mu \mathrm{mol})\end{array}$ & $\begin{array}{l}\mathrm{CO}_{2} \\
(\mu \mathrm{mol})\end{array}$ & $\begin{array}{l}\mathrm{C}_{6} \mathrm{H}_{12} \mathrm{O}_{6} \\
(\mu \mathrm{mol})\end{array}$ & $\begin{array}{l}\mathrm{HCOOH} \\
(\mu \mathrm{mol})\end{array}$ & & & & \\
\hline TC1 & 3.0 & 3.3 & 35.8 & 16.7 & 0.3 & Trace & 89.5 & 83.5 & 0.47 & 93.4 \\
\hline TC2 & 6.5 & 6.6 & 72.5 & 32.0 & 0.3 & 0.5 & 91.7 & 81.0 & 0.44 & 86.6 \\
\hline TC3 & 13.0 & 12.1 & 122.5 & 53.8 & 0.5 & 0.7 & 84.5 & 74.2 & 0.44 & 79.2 \\
\hline TC4 & 20.5 & 20.1 & 195.2 & 85.3 & 0.7 & 1.1 & 81.2 & 71.0 & 0.43 & 75.1 \\
\hline
\end{tabular}

Reaction conditions: $15 \mathrm{mg}$ sample in $50 \mathrm{ml} \mathrm{H}_{2} \mathrm{O}$, UV light irradiation, reaction time: $6 \mathrm{~h}$ for each cycle, 7 cycles performed in total, reaction temperature, 293-313 K. ${ }^{a}$ Total accumulated $\mathrm{H}_{2}$ and $\mathrm{CO}_{2}$ contents in 7 cycles subtract those generated from $\mathrm{TiO}_{2}$ sample (control test). ${ }^{b}$ Aqueous solution after photo-irradiation analyzed by HPLC. ${ }^{c}$ Calculated based on the complete conversion of glucose unit $\left(\mathrm{C}_{6} \mathrm{O}_{5} \mathrm{O}_{10}\right)$ to $\mathrm{H}_{2}$ and $\mathrm{CO}_{2}$ $\left(\mathrm{C}_{6} \mathrm{O}_{5} \mathrm{H}_{10}+7 \mathrm{H}_{2} \mathrm{O}=12 \mathrm{H}_{2}+6 \mathrm{CO}_{2}\right){ }^{d}$ Theoretical molar ratio of $\mathrm{CO}_{2} / \mathrm{H}_{2}$ is 0.5. ${ }^{e}\left(\left[\mathrm{CO}_{2}\right]+6\left[\mathrm{C}_{6} \mathrm{H}_{12} \mathrm{O}_{6}\right]+[\mathrm{HCOOH}]\right) / 6\left[\mathrm{C}_{6} \mathrm{O}_{5} \mathrm{H}_{10}\right]$.

Given that all the cellulose was decomposed, the lower C-balance suggests that more unknown soluble products (e.g. organic acids or sugars with $\mathrm{C}_{n}<3$ ) other than the standard sugar molecules detected by our HPLC were present in the aqueous solution.

Considering that the oxidation potentials of organic carbohydrates are more negative than the potential of water oxidation, ${ }^{21}$ thus it is more likely that the surface-bound cellulose were directly decomposed by the valence band holes, while the generated soluble intermediates in water could be further oxidized by holes or $\mathrm{OH}$ radicals. Eventually, all the organic products should be completely mineralized to $\mathrm{CO}_{2}$ by the $\mathrm{TiO}_{2}$ photocatalysis. However, the complete mineralization of the cellulose was not achieved and gradually reduced with the increased cellulose loading, which is probably due to the following reasons. Firstly, the anoxic conditions reduced the mineralization efficiency, as trace amounts of sugars and formic acid were still present after seven cycles. In addition, some unknown soluble products might be difficult to be further photo-oxidized because of the diffusion limit of free $\mathrm{OH}$ radials in water.

The pathway of cellulose decomposition is supposed to be quite complex, as only trace amounts of cellobiose and glucose along with the formic acid, were found as the soluble intermediates in our work. Owing to the labile characteristics of the intermediates, the identification of each intermediate was rather difficult and a lot of in situ characterization tools are required. Nevertheless, the surface bound cellulose and the soluble products generated during the whole process could be used as the sacrificial agents to enhance the $\mathrm{H}_{2}$ yields. The evolved $\mathrm{H}_{2}$ might stem from both the water reduction and the decomposition of cellulose degradation products (e.g. formic acid), since $\mathrm{H}_{2}$ production from photocatalytic degradation of formic acid has been proposed. ${ }^{22}$

Because of the simplicity of the immobilizing process and the well-known stability of titania, the reproducibility of catalyst would not be an issue in this approach. The optimization of catalysts and reaction conditions, analysis of liquid products, degradation pathway of cellulose and long-term stability test will be further studied in detail. In summary, simultaneous $\mathrm{H}_{2}$ production from photocatalytic water reduction and cellulose conversion was achieved. This approach provides an opportunity for harvesting valuable sugars via the in situ separation of sugars before undergoing further oxidation, which would require the development of appropriate reactor engineering. It has also demonstrated the feasibility of recovering hydrogen fuel from pure water without using valuable sacrificial agents and simultaneous conversion of cellulose into platform molecules by photocatalysis.

The authors thank the Engineering and Physical Sciences Research Council (EPSRC) for funding (EP/K036769/1; EP/ K022237/1) and Royal Society for a Wolfson Merit Award (JI).

\section{Notes and references}

1 A. J. Bard and M. A. Fox, Acc. Chem. Res., 1995, 28, 141-145.

2 A. Fujishima and K. Honda, Nature, 1972, 238, 37-38.

3 K. Maeda, K. Teramura, D. Lu, T. Takata, N. Saito, Y. Inoue and K. Domen, Nature, 2006, 440, 295.

4 Z. Zou, J. Ye, K. Sayama and H. Arakawa, Nature, 2001, 414, 625-627.

5 T. Ohno, L. Bai, T. Hisatomi, K. Maeda and K. Domen, J. Am. Chem. Soc., 2012, 134, 8254-8259.

6 X. Chen, L. Liu, P. Y. Yu and S. S. Mao, Science, 2011, 331, 746-750.

7 X. Du, J. Zhao, J. Mi, Y. Ding, P. Zhou, B. Ma, J. Zhao and J. Song, Nano Energy, 2015, 16, 247-255.

8 X. Wang, K. Maeda, A. Thomas, K. Takanabe, G. Xin, J. M. Carlsson, K. Domen and M. Antonietti, Nat. Mater., 2009, 8, 76-80.

9 Z. Zhang, Q. Lin, D. Kurunthu, T. Wu, F. Zuo, S.-T. Zheng, C. J. Bardeen, X. Bu and P. Feng, J. Am. Chem. Soc., 2011, 133, 6934-6937.

10 H. Husin, W.-N. Su, H.-M. Chen, H.-J. Pan, S.-H. Chang, J. Rick, W.-T. Chuang, H.-S. Sheu and B.-J. Hwang, Green Chem., 2011, 13, $1745-1754$.

11 J. Kim and W. Choi, Energy Environ. Sci., 2010, 3, 1042-1045.

12 R. M. Navarro, M. C. Sanchez-Sanchez, M. C. Alvarez-Galvan, F. del Valle and J. L. G. Fierro, Energy Environ. Sci., 2009, 2, 35-54.

13 N. Li, T. Zhang, M. Zheng, A. Wang, H. Wang, X. Wang and J. G. Chen, Angew. Chem., 2008, 120, 8638-8641.

14 Y. Zhang, A. Wang and T. Zhang, Chem. Commun., 2010, 46, 862-864.

15 J. C. Colmenares and R. Luque, Chem. Soc. Rev., 2014, 43, 765-778.

16 T. Kawai and T. Sakata, Nature, 1980, 286, 474-476.

17 H. Fan, G. Li, F. Yang, L. Yan and S. Zhang, J. Chem. Technol. Biotechnol., 2011, 86, 1107-1112.

18 M. Kaneko, R. Saito, H. Ueno, J. Nemoto and A. Izuoka, Catal. Lett., 2011, 141, 1199-1206.

19 G. Zhang, G. Kim and W. Choi, Energy Environ. Sci., 2014, 7, 954-966. 20 The complete conversion of glucose units into $\mathrm{H}_{2}$ and $\mathrm{CO}_{2}$ based on equation: $\left(\mathrm{C}_{6} \mathrm{H}_{10} \mathrm{O}_{5}\right)_{n}+7 n \mathrm{H}_{2} \mathrm{O} \rightarrow 12 n \mathrm{H}_{2}+6 n \mathrm{CO}_{2}$.

21 J. Wang and Z. Taha, Anal. Chem., 1990, 62, 1413-1416.

22 R. Chong, J. Li, Y. Ma, B. Zhang, H. Han and C. Li, J. Catal., 2014, 314, 101-108. 